\title{
Content analysis of comments posted on Australian online news sites reporting a celebrity admitting smoking while pregnant
}

\author{
Beverley Carrolla,b and Becky Freeman ${ }^{a}$
}

a Sydney School of Public Health, University of Sydney, NSW, Australia

b Corresponding author: bcarroll@uni.sydney.edu.au

\section{Article history}

Publication date: December 2016

Citation: Carroll B, Freeman B. Content analysis of comments posted on Australian online news sites reporting a celebrity admitting smoking while pregnant. Public Health Res Pract. 2016;26(5):e2651660. doi: http://dx.doi.org/10.17061/phrp2651660

\section{Key points}

- Negative societal attitudes towards pregnant women who smoke may affect the efforts of pregnant women to quit smoking

- Important health information tends to be overshadowed in celebrity health news stories

- Capacity building and resources would strengthen public health advocacy efforts to respond to online media stories about smoking during pregnancy

\section{Abstract}

Objectives: More than 12\% of Australian women who gave birth in 2012 reported smoking during pregnancy. Smoking during pregnancy may be under-reported as a result of negative societal attitudes towards pregnant women who smoke. This study sought to identify the extent and nature of online news readers' reactions to online news stories reporting Australian celebrity Chrissie Swan's admission of smoking while pregnant, and whether any smoking and pregnancy health information was included.

Study type: Quantitative media content analysis.

Methods: Readers' comments posted online in response to Australian online news stories and blogs reporting that Chrissie Swan had admitted smoking while pregnant were coded for inclusion in one of two categories: (1) opposing the judgement of Swan or (2) supporting the judgement of Swan. These comments were then grouped into seven frames. Comments that reflected the readers' own experiences of smoking during pregnancy and the inclusion of any helpful health information were also assessed.

Results: Comments that were critical of the judgement of Swan were most frequently found. Specific health facts and quit smoking advice rarely featured. Common frames were 'against making moral judgement' and 'smoking in pregnancy is wrong or harmful'.

Conclusions: The lack of comments addressing the misinformation about smoking and quitting during pregnancy suggests a potential role for public health practitioners in future smoking and pregnancy communication programs. The increase in the number of Australians participating in online communities and blogs provides the opportunity for capacity building and resources to enable a proactive and rapid public health response to media opportunities. 


\section{Introduction}

Maternal smoking remains a significant cause of infant death and illness. ${ }^{1,2}$ In Australia, $12.5 \%$ of women who gave birth in 2012 reported smoking during pregnancy. ${ }^{3}$ This figure could significantly underestimate actual smoking rates because the stigmatisation of pregnant women who smoke may result in pregnant women falsely reporting their smoking status. ${ }^{4}$ Stigmatisation may also undermine their help-seeking smoking cessation efforts ${ }^{5-7}$ and deter antenatal healthcare providers from intervening with clients. ${ }^{8}$

On 6 February 2013, Australian radio and television personality Chrissie Swan made a public announcement that she had been secretly smoking during her pregnancy, generating extensive media coverage in Australia. Swan framed her announcement as a confession and a moral failing, resulting in media coverage that focused on the societal judgement of pregnant women who smoke. ${ }^{9} \mathrm{~A}$ content analysis of online news stories reporting Swan's announcement found more content opposed to societal judgement of pregnant women who smoke $(57 \%)$ than content that supported negative attitudes towards pregnant women who smoke (43\%). The analysis also noted a lack of information encouraging and supporting pregnant women to quit smoking. ${ }^{9}$

Studies of the impact of celebrity health stories have reported improvements in health behaviours such as cancer screening and information seeking. ${ }^{10,11}$ However, any important, factual health information reported in these newsworthy 'human interest' storylines tends to be overshadowed by the celebrity-focused content, suggesting missed opportunities for public health practitioners to use these stories as a communication opportunity. ${ }^{9,12,13}$

Studies of online news reporting and reader responses are increasingly relevant. ${ }^{14}$ As of May 2014, two-thirds (10.79 million) of adult Australians accessed news online ${ }^{15}$ and more than half (54\%) of online Australians participated in online communities and blogs by posting comments about topics of interest, a rise of 10 percentage points from the previous reporting period in May 2013. ${ }^{16}$ This rise in internet use in Australia presents significant opportunities and challenges to implementing effective online tobacco control communication campaigns. ${ }^{17}$ Although evidence for using social media in campaigns by both the corporate and public health sectors is limited, case studies have demonstrated its merit as a cost-effective strategy for broadening campaign reach, supporting targeted smallscale projects and enabling real-time communications and interactions. There are also challenges, particularly for government agencies, such as having the capacity to respond and engage with online audiences. ${ }^{17,18}$

The high volume of online news stories and blog posts generated by Swan's announcement, and the large number of reader comments that followed ${ }^{9}$, present an opportunity to explore societal judgement of pregnant women who smoke from the readers' perspective. Understanding how tobacco control issues are framed in news stories by writers and their readers can usefully guide public health practitioner efforts to refute and reshape unsupportive commentary, and address misinformation about smoking and health issues. ${ }^{14,19-23}$

The aim of this research was to identify the extent and nature of online news readers' reactions to online news items that reported the 'Swan pregnant and admitting smoking' announcement and whether these comments provide any health information about the harms of smoking during pregnancy. Previous research relating to this celebrity news story ${ }^{9}$ showed that the media coverage focused on whether Swan or other women should be judged for smoking when pregnant. This study examines the arguments shared by online news readers that either supported or opposed this judgement. The extent that comments reflected the readers' experiences of smoking during pregnancy and the inclusion of any helpful health information were also assessed.

\section{Methods}

\section{Dataset}

The dataset was comments posted on 124 Australian online news items that reported the 'Swan pregnant and admitting smoking' story between 6 February 2013 and 18 February 2013, inclusive. ${ }^{9}$ Since media interest in the story was concentrated in the first few days following Swan's announcement and diminished considerably within 2 weeks, the search was limited to this 13-day period. Online news items included Australian national and regional newspapers, weekly magazines, news and entertainment sites, and blog sites. Many blog sites in Australia (www.mamamia.com.au) have become influential mass-reach media portals with large readerships ${ }^{24}$, and were therefore included in the study. Google News (news.google.com.au) and Google Blogs (the service is now disabled) were used to locate these online news items using search terms: "Chrissie Swan smoking" and "Chrissie Swan pregnant and smoking". ${ }^{9}$

\section{Procedure}

A content analysis is an appropriate research method for scrutinising text data. ${ }^{25} \mathrm{~A}$ large body of work has used this method to systematically categorise and quantify content in a dataset into frames and codes. ${ }^{14,21,26}$ The study applied Entman's description of framing, which involves selection and salience. ${ }^{25}$ To frame is to "select some aspects of a perceived reality and make them more salient in a communicating text, in such a way as to promote a particular problem definition, causal interpretation, moral evaluation, and/or treatment recommendation" for the item described. ${ }^{25}$ 
All online news items were recorded chronologically into a spreadsheet and all online poster comments were entered beneath their applicable news items in the spreadsheet. A poster is defined as someone who publishes ('posts') something, such as a message or an image, online. Each comment was then examined for eligibility for inclusion in the analysis. Because the focus of the study was to identify the main frames used in support or opposition to the judgement of Swan for smoking, eligible comments were those that could be assigned to one of two categories: (1) opposing the judgement of Swan or (2) supporting the judgement of Swan. Comments not eligible for inclusion in the study contained either no content relevant to the judgement of Swan's smoking, or were exchanges (mainly abuse) between posters. Examples included "who is she?", "so what?", "who cares?", "I dislike Swan", "using the story as publicity for her show" and "it's wrong to take photos of people in public".

As each comment was read for inclusion in the study and allocated to either category 1 or 2, shorthand titles such as "child abuse", "bad role model", "people judge smokers", "smoking is not illegal" or "Dr says cut back is best" were also entered against each comment to represent a frame. These frame descriptors were then examined and grouped according to frame similarities. Seven distinct frames were created across the two judgement categories. Each frame was given a code, and a code guide was developed. Using the code guide, each eligible comment was reread and allocated a code. Any information specific to a poster's own or another's experience of smoking during pregnancy, and information about specific health facts about smoking and pregnancy offered by a poster, were also noted.

Interrater reliability tests were undertaken for both the grouping of comments into the two societal judgement categories and for the coding of comments into the seven frames. Five individual coders firstly coded 10 pieces of content from the dataset to either societal judgement category 1 or 2 . The coders were given another 21 pieces of content from the dataset to code for the seven frames.

\section{Analysis}

Descriptive statistical analysis was used to assess the frequency of each frame. Kappa statistics were calculated to establish interrater reliability. ${ }^{27}$

\section{Results}

Of the 124 online news items, 61 included online news readers' comments. These included 36 news stories and 25 blog posts. A total of 4834 comments were published on the 61 news items. Half (49.98\%; $n=2416)$ of the comments met the criteria for analysis; 2418 (50.02\%) comments were excluded.

The results of the kappa tests for agreement were 0.93 for the grouping of comments into the two societal judgement categories and 0.71 for the coding of comments into the seven frames (a kappa value of $0.81-0.99$ is in the almost perfect agreement range, and a kappa value of $0.61-0.80$ is in the substantial agreement range). ${ }^{27}$

\section{Frequent comments regarding societal judgement of Swan for smoking during pregnancy}

Comments opposing the judgement of Swan for smoking in pregnancy were more frequently found $(58.11 \%$; $n=1404)$ than comments supporting criticism of Swan $(41.89 \% ; n=1012)$ (Table 1$)$.

Table 1. Frequency of comments opposing or supporting the judgement of Swan for smoking during pregnancy posted on online news and blog sites between 6 and 18 February 2013

\begin{tabular}{|c|c|c|c|}
\hline $\begin{array}{l}\text { Societal } \\
\text { judgement } \\
\text { category }\end{array}$ & $\begin{array}{c}\text { Number of } \\
\text { occurrences } \\
\text { on news } \\
\text { sites } \\
(n=1609)\end{array}$ & $\begin{array}{c}\text { Number of } \\
\text { occurrences } \\
\text { on blogs } \\
(n=807)\end{array}$ & $\begin{array}{c}\text { Total } \\
\text { number } \\
(\%) \text { of } \\
\text { occurrences } \\
(n=2416)\end{array}$ \\
\hline $\begin{array}{l}\text { 1: Comments } \\
\text { opposing the } \\
\text { judgement of } \\
\text { Swan (arguing } \\
\text { against the } \\
\text { criticism of Swan } \\
\text { for smoking while } \\
\text { pregnant) }\end{array}$ & 929 & 475 & $1404(58.11)$ \\
\hline $\begin{array}{l}\text { 2: Comments } \\
\text { supporting the } \\
\text { judgement of } \\
\text { Swan (arguing } \\
\text { in support of the } \\
\text { criticism of Swan } \\
\text { for smoking while } \\
\text { pregnant) }\end{array}$ & 680 & 332 & $1012(41.89)$ \\
\hline
\end{tabular}

\section{Inclusion of anecdotal smoking experience, and smoking and health information, in poster comments}

Nearly 1 in $10(9.77 \% ; n=236)$ of all comments posted mentioned either their own or their mother's smoking story, or past generations of women who smoked during pregnancy, to support their argument. Very few $(1.90 \%$; $n=46$ ) comments posted included any specific smoking in pregnancy health information or challenged comments that promoted safe levels of smoking during pregnancy. No comments posted by identifiable public health bodies or public health practitioners were found. 


\section{Framing of comments}

Tables 2 and 3 present the frequency of frames used in comments of the judgement of Swan, with a brief description of the content represented by each frame.

Across all comments in the frames either opposing (Table 2) or supporting (Table 3) the judgement of Swan, "smoking in pregnancy is wrong or harmful" and "against making moral judgements" each accounted for one-third of the total comments (33.69\%; $n=814$, and $32.20 \% ; n=$ 778 , respectively). The third most common frame across all comments was "have sympathy because quitting is hard" (13.20\%; $n=319$ ). Swan's smoking during her pregnancy was considered "not a big deal" by 1 in 10 (10.47\%; $n=253$ ) posters.

Table 2. Frequency of frames used in poster comments opposing the judgement of Swan posted on online news and blog sites between 6 and 18 February 2013

\begin{tabular}{|c|c|c|}
\hline Frame & $\begin{array}{l}\text { Total number } \\
\qquad(\%) \text { of } \\
\text { occurrences } \\
(n=2416)\end{array}$ & $\begin{array}{l}\text { Percentage of } \\
\text { occurrences } \\
\text { in comments } \\
\text { opposing the } \\
\text { judgement of } \\
\text { Swan }(n=1404)\end{array}$ \\
\hline $\begin{array}{l}\text { Against making moral } \\
\text { judgements } \\
\text { People should leave } \\
\text { Swan alone. } \\
\text { No one has the right to } \\
\text { judge her or others. } \\
\text { Swan is only human. } \\
\text { No-one's perfect. } \\
\text { It is her body, her baby, } \\
\text { her choice. } \\
\text { Smoking during pregnancy } \\
\text { is not illegal. }\end{array}$ & 778 (32.20) & 55.41 \\
\hline $\begin{array}{l}\text { Have sympathy because } \\
\text { quitting is hard } \\
\text { Quitting smoking is hard; } \\
\text { people need support. } \\
\text { Smoking is an addiction. }\end{array}$ & $319(13.20)$ & 22.72 \\
\hline $\begin{array}{l}\text { Not a big deal } \\
\text { Other things are more } \\
\text { harmful to baby. } \\
\text { Many women with healthy } \\
\text { babies have smoked. } \\
\text { Smoking too few cigarettes } \\
\text { to be a problem. } \\
\text { Doctor says cut down } \\
\text { is OK. }\end{array}$ & $253(10.47)$ & 18.02 \\
\hline $\begin{array}{l}\text { The stress of all this is } \\
\text { causing harm } \\
\text { The stress of people's } \\
\text { criticism of Swan is more } \\
\text { harmful. }\end{array}$ & $54(2.24)$ & 3.85 \\
\hline
\end{tabular}

Table 3. Frequency of frames used in poster comments supporting the judgement of Swan posted on online news and blog sites between 6 and 18 February 2013

\begin{tabular}{lcc}
\hline & $\begin{array}{c}\text { Total } \\
\text { number } \\
(\%) \text { of } \\
\text { occurrences } \\
(n=2416)\end{array}$ & $\begin{array}{c}\text { Percentage of } \\
\text { occurrences in } \\
\text { comments supporting } \\
\text { the judgement of } \\
\text { Swan }(n=1012)\end{array}$ \\
Frame & $814(33.69)$ & 80.43 \\
\hline Smoking in pregnancy \\
is wrong or harmful \\
Swan's smoking is \\
causing harm to baby. \\
Swan is knowingly \\
harming baby. \\
$\begin{array}{l}\text { Need to protect } \\
\text { baby's rights }\end{array}$ \\
$\begin{array}{l}\text { Swan should put her } \\
\text { baby first. }\end{array}$ \\
$\begin{array}{l}\text { Swan/society has a } \\
\text { duty of care to baby. }\end{array}$ \\
$\begin{array}{l}\text { Smoking during } \\
\text { pregnancy is child } \\
\text { abuse. } \\
\text { Smoking when } \\
\text { pregnant should be } \\
\text { illegal. } \\
\text { Society pays in } \\
\text { the end } \\
\text { Taxpayers will pay for } \\
\text { care of baby/smokers. }\end{array}$ \\
\end{tabular}

Illustrative quotes of analysed online news readers' comments (not edited to correct spelling or grammar) are included to explain and contextualise frames.

\section{Category 1: comments opposing the judgement of Swan}

The most common framing of comments opposing the judgement of Swan was "against making moral judgements" (55.41\%; $n=778)$. These comments argued that judging Swan, or any person, for smoking was not acceptable:

Why is it any of your business what a person does with their own body?28

\section{Quitting is hard}

The second most common frame found in comments in category 1 was "have sympathy because quitting is hard" $(22.27 \% ; n=319)$. These comments were sympathetic to Swan as a smoker experiencing difficulties with quitting, focused on the addictive nature of smoking, and called for people to support Swan with quitting smoking rather than shame and judge her.

It's sad when women smoke while pregnant, but you should give them support not kicks. It's a damn hard thing to get off. ${ }^{29}$ 


\section{Not a big deal}

The third most common frame in comments opposing the judgement of Swan was that Swan's smoking (or other women's smoking) during pregnancy was "not a big deal" (18.02\%; $n=253)$. These types of comments played down any health issues relating to Swan smoking during the pregnancy by focusing on the small number of cigarettes she was smoking, that past generations of women smoked during pregnancy, or on other environmental factors that can harm pregnant women and their unborn babies.

there are far worse things she could be doing in this world than having a few ciggy's while pregnant. ${ }^{28}$

\section{Category 2: comments supporting the judgement of Swan}

The most dominant frame in poster comments supporting the judgement of Swan was "smoking in pregnancy is wrong or harmful" (80.43\%; $n=814)$. Comments focused on the harm to the baby and described Swan's behaviour as uncaring, reckless and irresponsible.

it's a cot death risk. a very real one. ${ }^{30}$

These types of comments were more than four times more frequent than the next most common frame in this category.

\section{Need to protect baby's rights}

The second most common frame in comments in category 2 was primarily concerned with the issue of the baby's rights (17.69\%; $n=179$ ). These comments argued that it was right to judge Swan because the baby does not have a 'voice', smoking when pregnant is a form of child abuse, or unborn babies should be protected from the harm of smoking in the same way that smoking is illegal in cars with children.

As soon as she made the choice to carry the child to term, rather than abort, then 'rights of the child' became relevant if her actions impact the future health of her child. ${ }^{31}$

\section{Discussion}

As expected, the high volume of poster comments indicates that the story of a celebrity admitting smoking while pregnant captured the attention of online news consumers. The case that no-one has the right to judge others dominated this position, and many other posters reasoned that smokers need more understanding because quitting smoking can be difficult. However, many condemned Swan as a flawed individual, mother and wife; sanctioned the "public policing of pregnant women"; and reinforced negative attitudes towards pregnant women who smoke. ${ }^{6}$ While the malicious nature of many comments directed at Swan may be indicative of the negative and, at times, abusive environment of online forums in general32, a coherent public health response could have appealed for more understanding of Swan's struggle with quitting smoking. This response could have provided accurate smoking and health information, and important advice and information to support quitting.

A high proportion of comments that supported the judgement of Swan were based on the argument that Swan (by continuing to smoke while pregnant) was knowingly harming her baby. This indicates that there is a reasonably high level of awareness that smoking during pregnancy is an unsafe practice; however, this argument was used to justify the labelling of Swan as "uncaring", "reckless" and "selfish", rather than to encourage and support her to quit smoking.

Conversely, 1 in 10 posters challenged the harm caused by Swan smoking, with many posters stating that they had received medical advice that the safest strategy for avoiding harm to the unborn baby was reducing the number of cigarettes smoked during pregnancy, and that quitting completely was "too stressful" for the baby. In addition, 1 in 10 posters referred to their own or their mother's smoking and pregnancy experience to validate their assessment of the risk of Swan smoking during pregnancy. Only 46 poster comments cited any specific health harms to the baby from smoking, and it did not appear that any of these were posted by a public health agency or practitioner. Public health practitioners lost an opportunity to enter the debate and provide sound, evidence based information and advice regarding smoking during pregnancy, and to challenge myths about 'safe' smoking strategies for pregnant women.

Although a strong body of evidence has demonstrated that celebrity health news stories can have an impact on public health outcomes, key health information tends to be minimised within these stories. ${ }^{10-13}$ With news being commonly sourced from online outlets that promote reader participation through posted comments, strategies that support a proactive, real-time public health response would be useful. A communications strategy is needed that provides clear, accurate and accessible information, counters negative attitudes to smokers and supports smokers to make quit attempts, but also engages with online news readers. Training public health practitioners to be vigilant and alert to media opportunities for public health advocacy efforts, and providing resources, evidence based information and sample media responses that effectively support and enable this form of rapid public health response may be helpful. Given how powerful personal stories were to these online news consumers, ensuring that online public health communications include success stories and personal narratives is also important. Presenting a face and feelings alongside facts, especially for a highly emotive topic as smoking during pregnancy, appears worthwhile pursuing. Further research to explore the best way to engage with users and the types of messages 
that will cut through the overwhelming amount of content online should become research priorities.

The study was limited to readers' comments published on online news and blog sites. Negative emotions, commonly a feature in posts, may have influenced the nature of the online response to Swan's announcement. However, in regards to the two viewpoints about societal judgement of Swan that were explored in this study, there was no overwhelming response towards either viewpoint Also, comments that were highly emotional interactions between posters or those that expressed negative views about Swan and smoking in general were excluded from the study.

\section{Conclusion}

Opposition to the judgement of Swan for smoking during her pregnancy featured in the majority of readers' responses to the story included in this study. Personal moral principles, identification with Swan as a smoker and sympathy for Swan characterised this position. A more vitriolic voice condemned her for knowingly harming her unborn baby. Notably, there was a lack of commentary that addressed the range of misinformation regarding smoking and pregnancy presented by both sides of the debate. This suggests a key role for public health practitioners in future smoking and pregnancy communication programs. Public health advocacy strategies are needed to effectively use the popularity of online news sites to respond and engage with the community. Communication priorities include increasing understanding of the harms to the health of both mother and baby from smoking, and providing positive and supportive messages that encourage pregnant women to seek help to quit smoking. Formative research for the development of future smoking and pregnancy health promotion campaigns could explore the design and nature of online messaging.

\section{Acknowledgements}

We thank Sally Dunlop, Jesse Jansen, Andrea Smith, Susan Martinez and Kevin McGeechan for their assistance with the assessment of interrater agreement.

\section{Competing interests}

$\mathrm{BC}$ has received money from the Cancer Institute NSW, the Australian Government Department of Foreign Affairs and the Australian Sports Commission for consultancy services provided through her company, Carroll Communications Pty Ltd. BF has received money from the World Health Organization; the Sax Institute; Cancer Council NSW; the NSW Department of Health (now Ministry of Health); the Union for International Cancer Control; and the Asian Center for WTO \& International
Health Law and Policy, National Taiwan University, College of Law.

\section{Author contributions}

BC planned the study, conducted the research, analysed the data, and drafted and revised the manuscript. BF designed the research, analysed data and provided revisions to drafts of the manuscript.

\section{References}

1. National Center for Chronic Disease Prevention and Health Promotion (US) Office on Smoking and Health. The health consequences of smoking -50 years of progress: a report of the Surgeon General. Atlanta, GA: Centers for Disease Control and Prevention; 2014 [cited 2015 Nov 27]. Available from: www.surgeongeneral.gov/ library/reports/50-years-of-progress/

2. Dietz PM, England LJ, Shapiro-Mendoza CK, Tong VT, Farr SL, Callaghan WM. Infant morbidity and mortality attributable to prenatal smoking in the U.S. Am Journal Prev Med. 2010;39(1):45-52

3. Hilder L, Zhichao Z, Parker M, Jahan S, Chambers GM Australia's mothers and babies 2012. Canberra: Australian Institute of Health and Welfare and University of NSW; 2014 [cited 2016 Oct 14]. Available from: www.aihw.gov.au/WorkArea/DownloadAsset. aspx?id=60129550054

4. Dietz PM, Homa D, England LJ, Burley K, Tong VT, Dube SR, Bernert JT. Estimates of nondisclosure of cigarette smoking among pregnant and nonpregnant women of reproductive age in the United States. Am J Epidemiol. 2011;173(3):355-9.

5. Greaves L, Poole N, Okoli C, Hemsing N, Qu A, Bialystok L, O'Leary R. Expecting to quit: a best practices review of smoking cessation interventions for pregnant and post-partum women (2nd ed.). Vancouver: British Columbia Centre of Excellence for Women's Health; 2011 [cited 2014 Apr 30]. Available from: www.expectingtoquit.ca/documents/expecting-to-quitsinglepages.pdf

6. Wigginton B, Lee C. A story of stigma: Australian women's accounts of smoking during pregnancy. Critical Public Health. 2013;23(4):466-81.

7. Wigginton B, Lee C. Stigma and hostility towards pregnant smokers: does individuating information reduce the effect? Psychol Health. 2013;28(8):862-73.

8. Varescon I, Leignel S, Gérard C, Aubourg F, Detilleux M. Self-esteem, psychological distress, and coping styles in pregnant smokers and non-smokers. Psychol Rep. 2013;113(3):935-47.

9. Carroll B, Freeman B. 'The secret shame': a content analysis of online news reporting of a celebrity admitting smoking while pregnant. Health Promot J Austr. 2015;26(1):4-9. 
10. Metcalfe D, Price C, Powell J. Media coverage and public reaction to a celebrity cancer diagnosis. J Public Health. 2011;33(1):80-5.

11. Chapman S, Holding S, McLeod K, Wakefield M. Impact of news of celebrity illness on breast cancer screening: Kylie Minogue's breast cancer diagnosis. Med J Aust. 2005;183(5):247-50.

12. Hilton S, Hunt K. Coverage of Jade Goody's cervical cancer in UK newspapers: a missed opportunity for health promotion? BMC Public Health. 2010;10:368.

13. Kamenova K, Reshef A, Caulfield T. Angelina Jolie's faulty gene: newspaper coverage of a celebrity's preventive bilateral mastectomy in Canada, the United States, and the United Kingdom. Genet Med. 2014;16(7):522-8.

14. Freeman B. Tobacco plain packaging legislation: a content analysis of commentary posted on Australian online news. Tob Control. 2011;20(5):361-6.

15. Australian Communications and Media Authority. Communications report 2013-14. Canberra: Commonwealth of Australia; 2014 [cited 2016 Oct 14]. Available from: www.acma.gov.au/ /media/Research\%20 and\%20Analysis/Publication/Comms\%20Report\%20 2013\%2014/PDF/Communications\%20report\%20201314_ LOW-RES\%20FOR\%20WEB\%20pdf.pdf

16. Australian Communications and Media Authority. Communications report 2013-14 series: report 1 Australians' digital lives. Canberra: Commonwealth of Australia; 2015 [cited 2016 Oct 14]. Available from: www.acma.gov.au/ /media/Research\%20and\%20 Analysis/Research/pdf/Australians\%20digital\%20 livesFinal\%20pdf.pdf

17. Freeman B. New media and tobacco control. Tob Control. 2012;21(2):139-44.

18. Freeman B, Potente S, Rock V, Mclver J. Social media campaigns that make a difference: what can public health learn from the corporate sector and other social change marketers? Public Health Res Pract. 2015;25(2):e2521517.

19. Pederson LL, Nelson DE, Babb S, London J, Promoff G, Pechacek T. News media outreach and newspaper coverage of tobacco control. Health Promot Pract. 2012;13(5):642-7.

20. Freeman B, Chapman S, Storey P. Banning smoking in cars carrying children: an analytical history of a public health advocacy campaign. Aust N Z J Public Health. 2008;32(1):60-5.
21. Kline KN. A decade of research on health content in the media: the focus on health challenges and sociocultural context and attendant informational and ideological problems. J Health Commun. 2006;11(1):43-59.

22. Smith KC, Niederdeppe J, Blake KD, Cappella JN. Advancing cancer control research in an emerging news media environment. J Natl Cancer Inst Monogr. 2013;2013(47):175-81.

23. McLeod K, Wakefield M, Chapman S, Smith KC, Durkin S. Changes in the news representation of smokers and tobacco-related media advocacy from 1995 to 2005 in Australia. J Epidemiol Community Health. 2009;63(3):215-20.

24. Roy Morgan Research. Mamamia website audience grows another 75,000 in latest quarter to 635,000 visitors a month. Melbourne: Roy Morgan Research; 2014 [cited 2016 Oct 14]. Available from: www.roymorgan.com/ findings/5741-mamamia-website-audience-growth-trendjune-2014-201408190056

25. Entman RM. Framing: toward clarification of a fractured paradigm. Journal of Communication. 1993;43(4):51-8.

26. Jenssen BP, Klein JD, Salazar LF, Daluga NA, DiClemente RJ. Exposure to tobacco on the internet: content analysis of adolescents' internet use. Pediatrics. 2009;124(2):e180-6.

27. Viera A, Garrett J. Understanding interobserver agreement: the kappa statistic. Fam Med. 2005;37:360-3.

28. Casamento J. 'I knew it was wrong': Chrissie Swan admits to smoking while pregnant. The Sydney Morning Herald; 2013 Feb 6 [cited 2013 Oct 30]. Available from: www.smh.com.au/lifestyle/life/i-knew-it-was-wrongchrissie-swan-admits-to-smoking-while-pregnant20130206-2dxv2.html

29. Davies A. Pregnant women who smoke are easy targets for the morality police. Sydney Morning Herald; 2013 Feb 7 [cited 2015 Nov 26]. www.smh.com.au/ opinion/society-and-culture/pregnant-women-who-smokeare-easy-targets-for-the-morality-police-20130206-2dyx5. html\#ixzz2KN6AyeWZ (URL no longer active).

30. Mamamia Team. Chrissie Swan confesses to smoking while pregnant. Mamamia; 2013 Feb 7 [cited 2015 Nov 26]. Available from: www.mamamia.com.au/news/chrissie-swans-smokingconfession-could-she-have-handled-it-any-better/

31. Ford C. Why are we so angry at Chrissie Swan? Daily Life; 2013 February 6 [cited 2016 Oct 14]. Available from: www. dailylife.com.au/action/printArticle?id $=4009818$

32. Chmiel A, Sobkowicz P, Sienkiewicz J, Paltoglou G, Buckley K, Thelwall M, Holyst J. Negative emotions boost user activity at BBC forum. Physica A: Statistical Mechanics and its Applications. 2011;390(16):2936-44.

\section{Copyright: (c)}

(c) 2016 Carroll and Freeman. This article is licensed under the Creative Commons Attribution-NonCommercial-ShareAlike 4.0 International Licence, which allows others to redistribute, adapt and share this work non-commercially provided they attribute the work and any adapted version of it is distributed under the same Creative Commons licence terms. See: www.creativecommons.org/licenses/by-nc-sa/4.0/ 